\title{
El proceso de renovación de la arquitectura sagrada católica a través de la normativa y el magisterio eclesiásticos (1969-2008)
}

\author{
The Process of Renewal of Catholic Sacred Architecture through Ecclesiastical Norms and \\ Magisterium (1969-2008)
}

Fernando López-Arias·Pontificia Università della Santa Croce (Roma, Italia), f.lopezarias@pusc.it

Recibido: 22/07/2019

Aceptado: 12/12/2019

(c) BY-NC https://doi.org/10.17979/aarc.2019.6.0.6210

\section{RESUMEN}

La reforma de la liturgia promovida por el Concilio Vaticano II (1962-65) implicó una renovación de los criterios para la construcción de edificios de culto en la Iglesia católica. En una primera fase (1969-88), dicha renovación fue asimilada rápidamente por la arquitectura sagrada del momento. Posteriormente, una serie de dinámicas de la liturgia católica y la arquitectura contemporánea determinaron paulatinamente el desarrollo de un nuevo período para la arquitectura sagrada contemporánea (1988-2008).

El artículo concluye tratando de identificar las tendencias de evolución de la arquitectura sagrada católica de los últimos quince años, en las que han tenido una especial relevancia algunos pronunciamientos recientes del magisterio papal: valorización de la dimensión icónica de la iglesia; sacralidad; orientación; protagonismo del ambón; relevancia de la reserva eucarística; uso extralitúrgico y devocional; e iconografía y moderación de la abstracción.

\section{PALABRAS CLAVE}

Reforma litúrgica, arquitectura sagrada contemporánea, conferencias episcopales, Magisterio, postmodernidad.

\section{ABSTRACT}

The reform of the Liturgy after the Second Vatican Council (1962-65) implied a renewal of the criteria for the construction of buildings for worship in the Catholic Church. In a first phase (1969-88) this renovation was quickly assimilated by the sacred architecture of the time. Subsequently, a series of historical processes of the Catholic Liturgy and contemporary architecture gradually determined the development of a new period for contemporary sacred architecture (1988-2008).

The article concludes trying to identify the dynamics of evolution of Catholic sacred architecture in the last fifteen years, in which some recent documents of the Papal Magisterium have had a special relevance: valorization of the iconic dimension of church-building; sacredness; orientation; prominence of the ambo; relevance of the place where the Eucharist is reserved; extraliturgical; and devotional use of the temple and iconography and moderation of abstraction.

\section{KEYWORDS}

Liturgical Reform, Contemporary Sacred Architecture, Episcopal Conferences, Magisterium, Postmodernity.

Cómo CITAR: López-Arias, Fernando. 2019. «El proceso de renovación de la arquitectura sagrada católica a través de la normativa y el magisterio eclesiásticos (1969/2008)». Actas de Arquitectura Religiosa Contemporánea 6: 26-41.

https://doi.org/10.17979/aarc.2019.6.0.6210. 


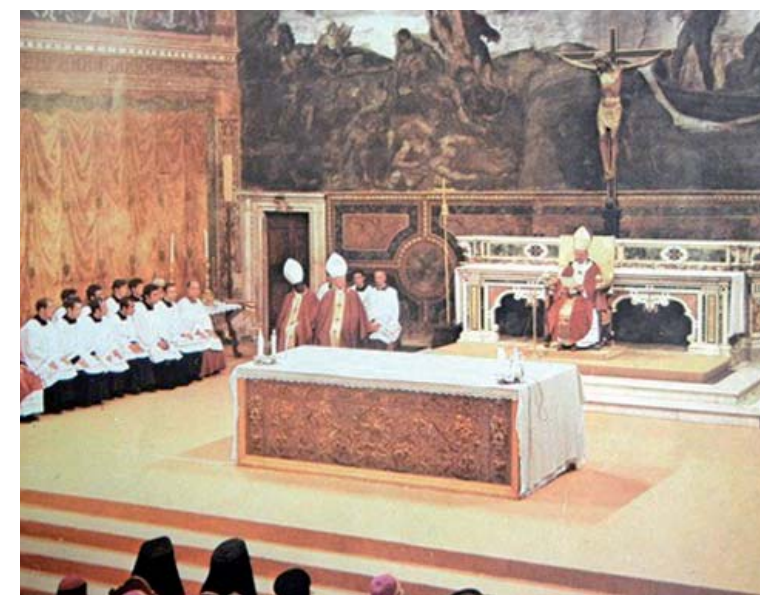

\section{A CINCUENTA AÑOS DEL MISAL ROMANO}

En 2019 se cumplen cincuenta años de la publicación de la Institutio generalis (Ordenación general) del Misal Romano de Pablo VI. Esta Institutio era una larga y detallada introducción teológica, ritual y pastoral al nuevo misal, que comenzó a usarse propiamente pocos meses después (marzo de 1970). En su capítulo V (nn. 253-280), bajo el título "Disposición y ornato de las iglesias para la celebración de la Eucaristía", se detallaban unas completas instrucciones sobre la disposición de los principales lugares litúrgicos (altar, ambón, sede), los ámbitos celebrativos (presbiterio, nave, capilla eucarística, coro) y la iconografía de la iglesia.

El Misal de san Pablo VI (Fig. 01) constituía el fruto quizás más significativo de la renovación de la liturgia deseada por el Concilio Vaticano II, a través de la constitución Sacrosanctum Concilium -en adelante $S C$ - (n. 25). La misma constitución manifestaba su deseo de que fueran revisadas sin dilación las normas y cánones sobre el modo de construir los edificios de culto, como consecuencia de la renovación de los ritos (SC 128). Este capítulo V del Misal Romano venía a cumplir este deseo para el caso de la misa. ${ }^{1}$

Aunque de hecho en los años inmediatamente precedentes a 1969 comienzan a construirse algunos significativos edificios de culto según este espíritu de
Fig. 01. Pablo VI preside la Eucaristía en la Capilla Sixtina durante la III Asamblea General del Sínodo de los Obispos (27/09/1974).

renovación, ${ }^{2}$ consideramos que el Misal Romano de Pablo VI constituye el auténtico punto de inflexión para la renovación de la arquitectura sagrada católica en el siglo XX, siempre que este fenómeno sea considerado en su globalidad (en todo el mundo). A partir del Misal Romano, el modo de organización del espacio celebrativo según el espíritu del Vaticano II se encontró en pocos años al alcance de amplios sectores culturales del mundo católico, gracias a las sucesivas traducciones del Misal.

En esta comunicación nos proponemos describir el proceso de renovación de la arquitectura litúrgica católica a partir de 1969-70 y hasta 2008 (cuando concluyó la reforma de los libros litúrgicos), tratando de identificar las principales tendencias de evolución a lo largo de este complejo proceso histórico. Para ello nos serviremos en buena medida de la normativa y el magisterio eclesiásticos sobre la arquitectura sagrada de este período, tanto a nivel universal (documentos emitidos por el papa o los organismos de la Curia Romana) como regional (a cargo de las conferencias episcopales nacionales).

Naturalmente, la arquitectura cristiana no se desarrolla únicamente al ritmo de la publicación de documentos eclesiásticos. La arquitectura, como fenómeno artístico, cambia junto con la cultura y la misma sociedad. Por ello, este proceso está sometido a dinámicas legadas a la liturgia, al Magisterio y a la propia arquitectura de cada época. ${ }^{3}$ 


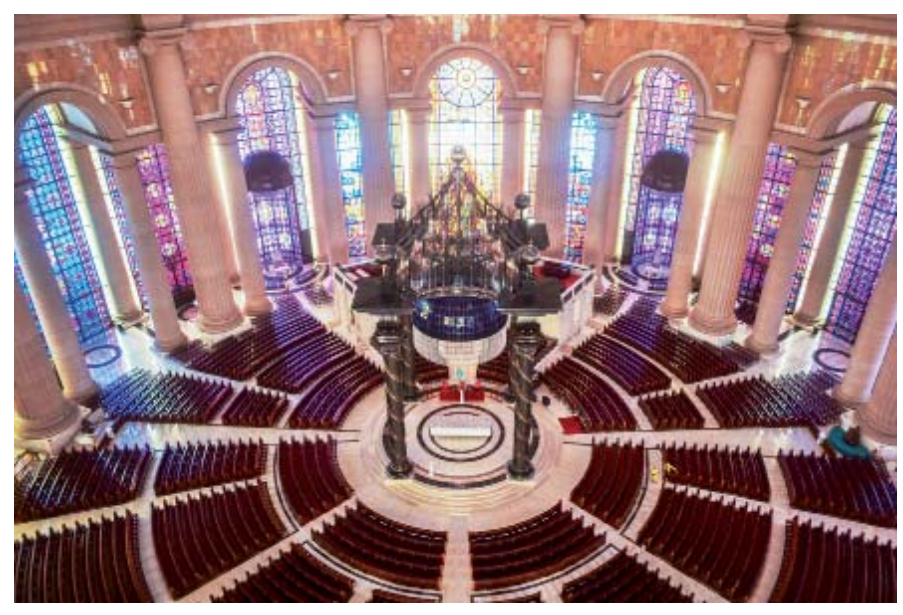

Fig. 02. Pierre Fakhoury, Basílica de Notre Dame de la Paix, Yamoussoukro (Costa de Marfil, 1985-90).

Fig. 03. Wojciech Pietrzyk, Arca del Señor, Nowa Huta (Polonia, 1969-77).

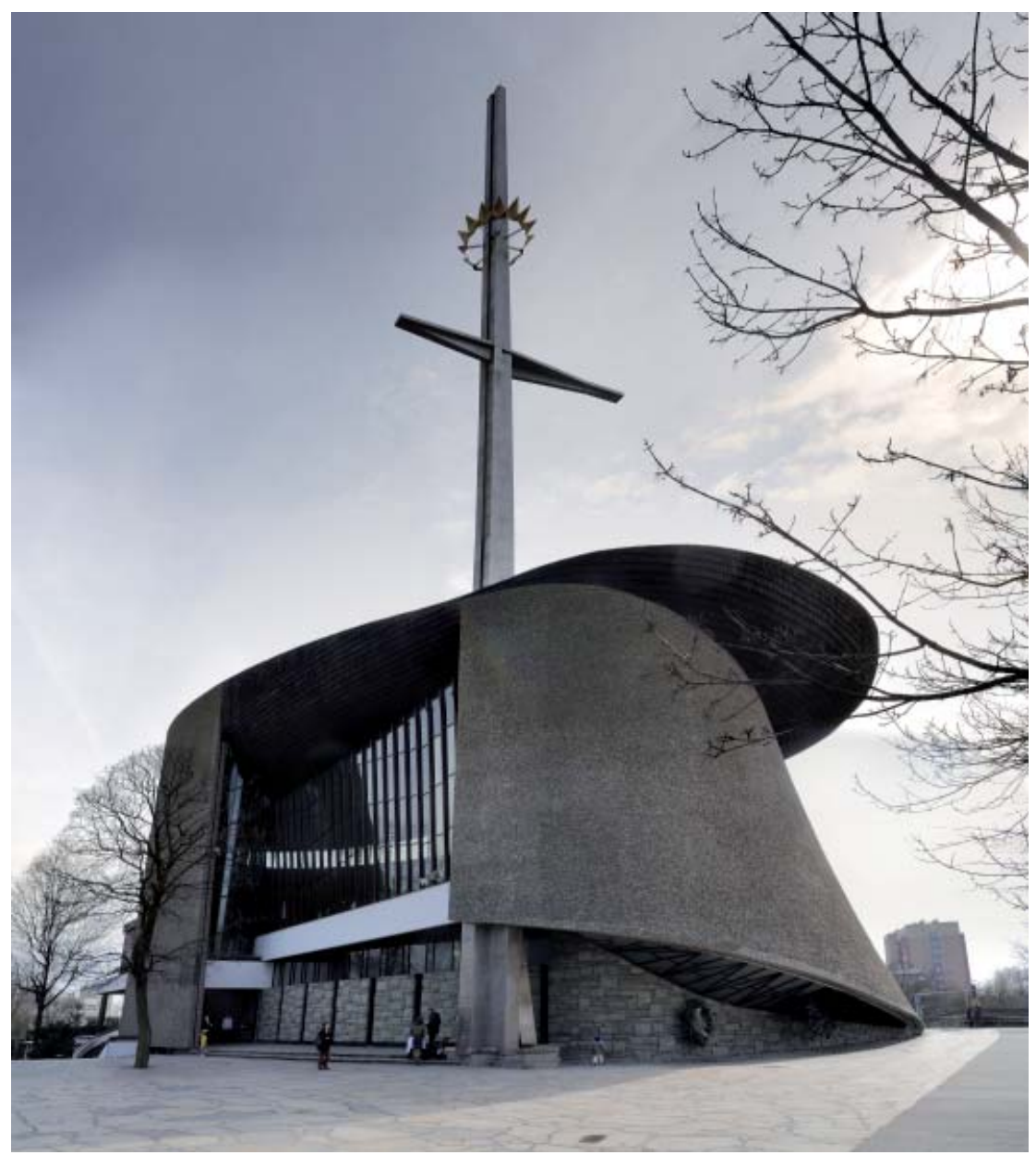




\section{DIFUSIÓN GLOBAL DE LA REFORMA ARQUITECTÓNICA (1969-88)}

La arquitectura sagrada integró rápidamente el espíritu de renovación que el Concilio Vaticano II auspició para el arte cristiano. Los principios generales para la construcción del espacio celebrativo descritos en la Institutio del Misal fueron interpretados, en los años sucesivos, en áreas geográficas y contextos culturales muy distintos. Algunas conferencias episcopales publicaron normativas nacionales para la edificación de culto o para la adecuación de antiguos espacios celebrativos según el espíritu de la liturgia renovada. Estos son los casos de Francia (1971), Irlanda (1972), Estados Unidos (1978), Inglaterra y Gales (1984), España (1987) y Alemania (1988). ${ }^{4}$

El programa arquitectónico que formulaban no era, en realidad, una completa novedad. Era el fruto de las experiencias arquitectónicas de los últimos decenios en Europa imbuidas por el Movimiento Litúrgico, especialmente en Alemania, Francia y Austria en los años cicuenta. ${ }^{5}$ Junto al fomento de la participación activa (SC 14 y 21), verdadero leit motiv del Movimiento Litúrgico, el otro aspecto decisivo de las enseñanzas conciliares para la nueva forma del edificio de culto fue la eclesiología. La dimensión fuertemente simbólica de la iglesia-edificio, como imagen de la Iglesia-comunidad cristiana, hacía del edificio de culto un medio privilegiado para expresar la renovada teología conciliar sobre la Iglesia. La disposición general de la asamblea permitía representar los dos aspectos de la eclesiología del Vaticano II que suscitaron mayor interés y entusiasmo en los años 60 y 70: la Iglesia como Communio (Koinonía) o comunidad en Cristo (Lumen Gentium 1-8 y Christus Dominus 1-7), y como Pueblo de Dios (Lumen Gentium 9-17).

Las consecuencias formales de esta búsqueda simbólica de una imagen de la Iglesia a través de la arquitectura fueron fundamentalmente dos. Por un lado, la acentuación de la unidad espacial y volumétrica del espacio de los fieles (nave) y de los ministros ordenados (presbiterio y ábside), evitándose o reduciéndose notablemente los elementos de distinción entre ambos (arco triunfal, gradas, comulgatorios). Por otra parte, el favorecimiento de la estructura centralizada frente a la longitudinal, que facilitaba la percepción de la comunidad como asamblea litúrgica reunida en comunión fraterna (van Bühren 2008, 395-397). Paradigmáticos son los enormes santuarios de Nuestra Señora Aparecida en Brasil (1955-80) y de Notre Dame de la Paix, en Yamoussoukro (Costa de Marfil, 1985-90), que recurren a la planta central para la disposición de la asamblea litúrgica: cruciforme en el primer caso y circular en el segundo (Fig. 02).

Las normas del magisterio eclesial después de $S C$ apenas dieron orientaciones sobre la forma y el material de construcción del edificio de culto. Esta apertura permitía a arquitectos y clientes una gran libertad, prefiriendo un lenguaje más plástico, en planta y alzado, con disposiciones de los lugares litúrgicos que rompían la simetría tradicional de este tipo de espacios. La arquitectura eclesiástica postconciliar podía convertirse en un campo experimental en virtud también de la estructura, que solía exigir grandes luces. Las posibilidades técnicas que ofrecía el hormigón armado, herencia del brutalismo arquitectónico, contribuyeron a que el edificio de culto de la iglesia católica - análogamente a la arquitectura secular - se desarrollara en una gran variedad estilística (van Bühren 2008, 373-374).

La mayor libertad formal tuvo como consecuencia el abandono del universo simbólico tradicional que se asociaba a la forma de un templo católico (Schloeder 1998, 168-224). Al mismo tiempo, la absolutización de la función litúrgica para el diseño de la iglesia relegaba a un plano secundario la función extralitúrgica del edificio de culto, ${ }^{6}$ lo que incluía el ejercicio de las prácticas de devoción personal y de la piedad popular. La consecuente depuración iconográfica afectaba a las imágenes tanto litúrgicas como devocionales, tanto en el interior como en el exterior del edificio (van Bühren 2008, 602).

Algunos ejemplos que expresan el espíritu de este período son la iglesia del Arca Pana en Nowa Huta (Polonia, 1969-77), de Wojciech Pietrzyk, con su expresividad formal (Fig. 03); el nuevo santuario de Nuestra Señora de Guadalupe, de Pedro Ramírez Vázquez, José Luis Benlliure Galán y fray Gabriel Chávez de la Mora, en Ciudad de México (1972- 
75), donde las particulares necesidades funcionales del edificio fueron resueltas convenientemente con un alarde técnico; el santuario de Nuestra Señora de los Llanos, en Coromoto (Venezuela, 1975-96), de Erasmo Calvani, rotunda construcción de hormigón armado, o la catedral de la Resurrección, en Evry (Francia, 1988-95), de Mario Botta, en la que, pese a las intenciones del arquitecto, su forma adolece de falta de cualidad simbólico-trascendente.

\section{UN NUEVO PERÍODO PARA LA ARQUITECTURA SAGRADA (1988-2008)}

Hacia finales de los años ochenta, una serie de acontecimientos en la liturgia católica y en la arquitectura favorecen que se pueda hablar de un nuevo período para la historia del edificio de culto. Desde el punto de vista eclesial, el momento de inflexión se corresponde, aproximadamente, con los veinticinco años de la publicación de SC (1963-1988). Este momento coincide, en el caso de la arquitectura, con la acentuación de la crisis del funcionalismo. El final de esta etapa - que hemos situado en 2008- se determina con los últimos hitos de la reforma litúrgica: la publicación en 2004 del último libro de la liturgia renovada (el Martirologio Romano, que tuvo una primera edición en 2001) y de la versión revisada de la tercera edición (2002) del Misal Romano, en 2008.

Algunos documentos magisteriales sobre la liturgia durante el pontificado de Juan Pablo II, como la carta apostólica Vicesimus quintus annus (1988) ${ }^{7}$ - que desea hacer una suerte de balance de la reforma promovida por el Concilio- o la instrucción de la Congregación para el Culto Divino Liturgiam authenticam (2001), hacen pensar que, hacia la segunda mitad de los años ochenta, inicia efectivamente una nueva etapa en el recepción de la reforma litúrgica. ${ }^{8}$ Dicho punto de inflexión se interpreta en ocasiones en sentido continuista, es decir, como el resultado de la profundización en los principios de la reforma litúrgica conciliar (Hoping 2011, 340-341; Mannion 1998, 11-48). También puede leerse en sentido de discontinuidad respecto a la etapa precedente, de dos modos diversos. Por un lado, interpretándolo como un movimiento eclesial de reacción ante el modo de aplicar la reforma litúrgica del Concilio
(Nichols 1996; Mosebach 2007), llegando a hablar de «reforma de la reforma» (Gamber 1989; Kocik 2003; Bux 2008). O incluso como una involución del Magisterio respecto al espíritu del Vaticano II (Cabié 2000, 3-14; Baldovin 2010, 397-402; Faggioli 2016, 201-217). En cualquier caso podemos decir —aún con el riesgo de simplificar excesivamente la historia - que mientras la primera fase de la reforma estuvo caracterizada por subrayar la dimensión más exterior de la participación activa, el Magisterio condujo progresivamente la Iglesia hacia la consideración de los aspectos más espirituales e internos de la participación de los fieles en el culto.

Un hito importante de nuestra historia fue, sin duda, el nuevo Catecismo universal de la Iglesia católica, publicado en 1993, fruto maduro de la recepción del Vaticano II por parte de la Iglesia. El Catecismo dedica una sección (nn. 1180-1186) titulada "¿Dónde celebrar?" a describir el lugar de culto cristiano. ${ }^{9}$ Tras una introducción sobre la naturaleza teológica del edificio de culto (nn. 1179-1180), el Catecismo describe el programa funcional de la iglesia: celebración litúrgica y oración personal (nn. 1181 y 1185). Concluye con un punto dedicado a la dimensión simbólica del templo y de sus partes (n. 1186).

Posiblemente favorecido por este clarificador pronunciamiento del Magisterio, desde principios de los años noventa el ritmo de publicación de normativas de las conferencias episcopales para la construcción o adecuación litúrgica de edificios de culto se incrementa. Hasta 2008, los países que publicaron estas instrucciones fueron Italia (1993 y 1996), Irlanda (1993), Puerto Rico (1995), Canadá (1999), Estados Unidos (2000), Alemania (2003), España (2006) e Inglaterra y Gales (2006).

Por otro lado, van Bühren ha identificado en este período un particular esfuerzo, por parte del magisterio eclesial, por favorecer el compromiso pastoral de la Iglesia en el campo del arte (van Bühren 2008, 601-602). Paradigmático de este momento es la conocida Carta a los artistas de Juan Pablo II (1999), donde aboga por renovar la tradicional alianza entre el arte y el evangelio: «la Iglesia tiene necesidad de arquitectos» (n. 12). ${ }^{10}$ 
El guante lanzado por la Iglesia fue, de algún modo, acogido por el mundo de la arquitectura contemporánea. En los últimos veinticinco años algunos importantes arquitectos del panorama internacional se han interesado por el tema de la arquitectura sagrada, realizando significativos templos católicos: Alvaro Siza (Santa María, en Marco de Canaveses, Portugal, 1992-96); Steven Holl (capilla de San Ignacio, Seattle, 1994-97) (Fig. 04); Rafael Moneo (Catedral de Nuestra Señora de los Ángeles, Los Ángeles, 1998-2002); Richard Meier (Dios Padre Misericordioso, Roma, 1998-2003) o Renzo Piano (Santuario de San Pío de Pietrelcina, San Giovanni Rotondo, 1994-2004).

Un último apunte sobre el espacio litúrgico en este período. El concepto de Communio-Raume (literalmente espacio para la comunión o comunional) surge a finales de los años noventa en Alemania, gracias a las aportaciones de los liturgistas de Münster, Klemens Richter (Richter 1998b) y de Bonn, Albert Gerhards (Gerhards 1999; Sternberg, Zahner, y Gerhards 2003). ${ }^{11}$ Dicha propuesta ideaba una distribución del espacio litúrgico que combinaba la planta central — que favorecía la percepción de la dimensión comunitaria de la celebración- y la doble focalización simbólica en el altar y el ambón. El resultado es una planta elíptica en cuyo eje mayor o menor se sitúan los lugares celebrativos principales: especialmente las dos mesas del pan y la palabra, aunque encontramos en ocasiones también la sede y la fuente bautismal. Pese a lo sugestivo de la propuesta, su incidencia efectiva a nivel global fuera de algunas experiencias en Alemania, Austria, Bélgica y Francia - ha sido limitada.

\section{DINÁMICAS DE EVOLUCIÓN DE LA ARQUITECTURA SAGRADA EN EL NUEVO SIGLO}

La hipótesis que nos gustaría ahora proponer consiste en que ciertos aspectos de la tradición arquitectónica cristiana un poco olvidados en los últimos decenios, acaso como consecuencia de la absolutización de la funcionalidad litúrgica y de la dimensión exterior de la participación de los fieles, han sido paulatinamente reintegrados en el proyecto del edificio de culto en los últimos quince años. ${ }^{12}$ En parte, esta evolución es fruto de la misma dinámica de la historia: han pasado ya más de cincuenta años del inicio de la Reforma litúrgica, y es más sencillo construir un edificio de culto con una mayor distancia respecto a las circunstancias contingentes y a las opiniones del momento en que esta se forjó. Por otra parte, el desarrollo de la teología litúrgica ha abierto nuevas perspectivas para el estudio del culto cristiano, mientras que las aportaciones de la arqueología y de la historia de la antigüedad han permitido entender mejor algunos aspectos sobre los orígenes del culto y la arquitectura cristianos (Gerhards 2007, 174-182).

En el origen de estas dinámicas de evolución se encuentran naturalmente factores de tipo no solo litúrgico (Debuyst 2003, 105-122), sino también magisterial, teológico, arquitectónico y sociológico. Paul Post ha señalado agudamente cómo, en realidad, nos encontramos ante manifestaciones en ámbitos diversos, pero complementarios, de un único movimiento histórico de la cultura occidental (Post 2006, 264-79). Desde el punto de vista sociológico, junto a la crisis de la práctica religiosa, hay una cierta desconfianza hacia la modernidad y el intelectualismo. Es un momento que favorece el esteticismo y la sacralización (como reacción ante la acentuación de la secularización), al tiempo que se intentan recuperar las raíces del pasado a través de una valorización de la historia no ideológica, sino más bien folclórica y formalista (Post 2006, 275-279; van Bühren 2008, 395).

Seguidamente trataremos de definir algunas de estas tendencias, señalando en cada caso los factores arquitectónicos, litúrgicos y los pronunciamientos del magisterio de la Iglesia que permiten de algún modo interpretarlas.

\section{Valorización de la dimensión icónica}

Una de las formas que adquirió la contestación al Movimiento moderno, a partir de la segunda mitad de los años sesenta, fue el cambio en el modo de interpretar la historia y la tradición, también desde el punto de vista formal (De Fusco 1996, 453). A este rasgo programático de la así llamada arquitectura postmoderna, se pueden añadir su deseo de comuni- 

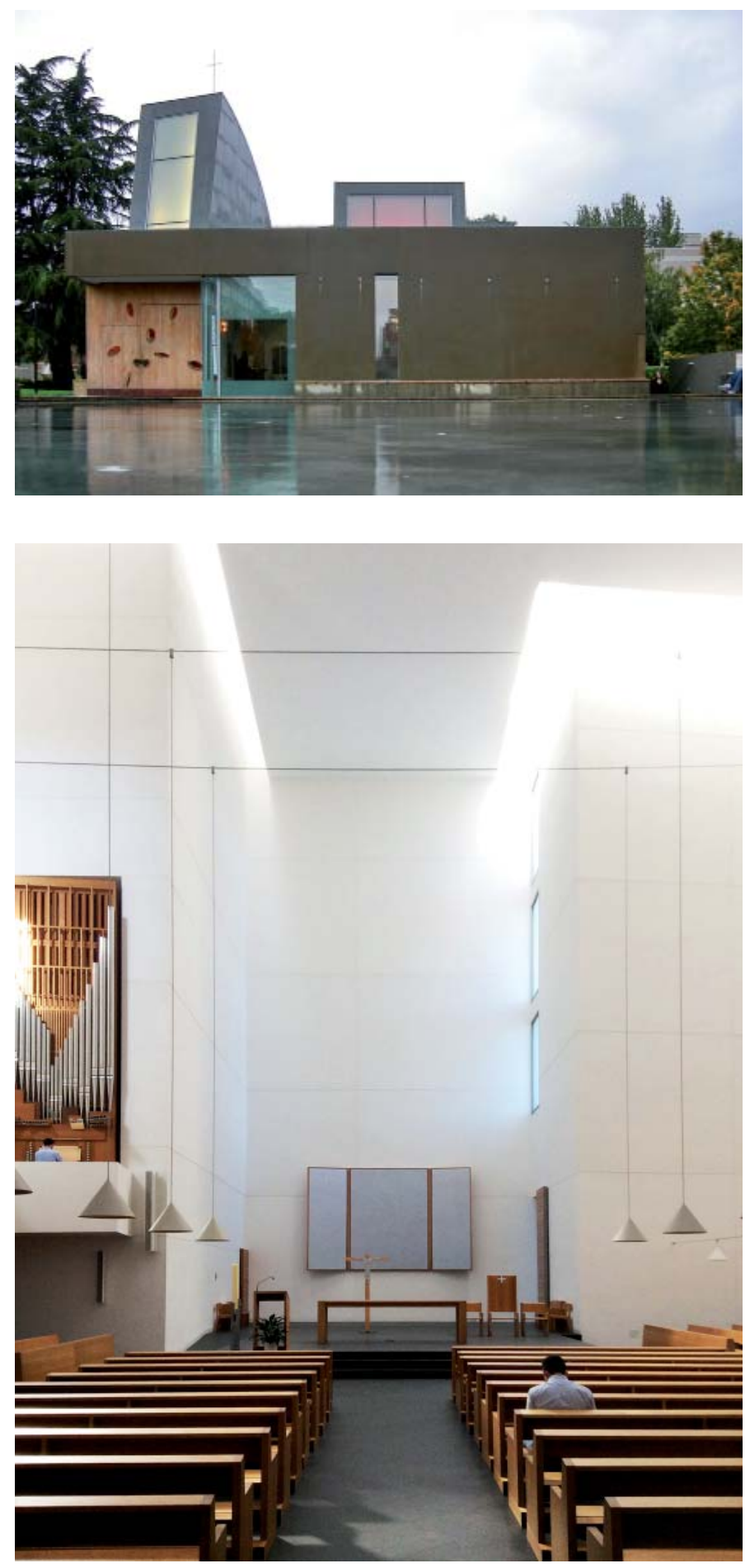

Fig. 04. Steven Holl, Capilla de San Ignacio, Seattle (EEUU, 1994-97).

Fig. 05. Rafael Moneo, lesu, San Sebastián (España, 2007-11). 
catividad; su aprecio por la decoración; su sintonía con algunas exigencias populares; una cierta tendencia a la abundancia y al gasto, junto al gusto por lo transitorio y efímero, que termina en el eclecticismo (De Fusco 1996, 509-510). ${ }^{13}$ Por lo que respecta al edificio de culto, la reivindicación de su función icónica en los últimos decenios - una cierta «vuelta a la monumentalidad» (Longhi 2017, 85)—implicará una acentuación de la función simbólica y comunicativa de la iglesia. Juan Pablo II, en la encíclica Ecclesia de Eucharistia (2003), aludía expresamente a la dimensión sacramental del arte sagrado, es decir, a su capacidad comunicativa como vehículo para penetrar en el Misterio (n. 50).

En este amplio contexto podemos situar el movimiento que surge en Estados Unidos a principios de los años noventa, que propone la recuperación del lenguaje clásico para la arquitectura cristiana. Es lo que Kieckhefer ha denominado la «contrarreacción tradicionalista» (Kieckhefer 2004, 275-278). En esta corriente podemos situar el santuario de la Virgen de los Dolores, de Barbara Bielecka, en Licheñ (Polonia, 1994-2004) y la capilla del Thomas Aquinas College, de Duncan Stroik, en Santa Paula (EEUU, 20082009). Con un decidido lenguaje moderno, en cambio, la iglesia del Sagrado Corazón de Jesús, de Allmann Sattler Wappner Architekten, en Múnich (1997-2004) afirma su vocación significativa en el tejido urbano.

\section{Sacralidad}

Es conocido que el debate sobre la desacralización en los años cincuenta y sesenta tuvo una fuerte influencia en la liturgia cristiana y, en particular, en su espacio celebrativo (Kieckhefer 2004, 282-287). Sin embargo, la sociología religiosa ha identificado un movimiento de vuelta a lo sagrado en las últimas décadas, como reacción al materialismo a ultranza (Introvigne 1996, 5-22). Esta renovada sensibilidad con frecuencia no se canaliza a través de formas institucionales, sino que se expresa en formas de espiritualidad de tipo más subjetivo, individualista, ecológico e informal.

En este contexto, en Ecclesia de Eucharistia (2003), Juan Pablo II advertía sobre la tentación de banalizar la celebración eucarística, olvidando su dimensión trascendente y sacrificial: «el banquete eucarístico es verdaderamente un banquete sagrado, en el que la sencillez de los signos contiene el abismo de la santidad de Dios» (n. 48). Consideramos que un rasgo esencial de la arquitectura cristiana de los últimos quince años es precisamente la mayor valoración de la dimensión sagrada o trascendente de la arquitectura. ${ }^{14}$ Citamos tres obras recientes que manifiestan este renovado interés por lo sagrado: la capilla de San Nicolás de Flüe, de Peter Zumthor, en Mechernich (Alemania, 2007); la iglesia parroquial Iesu, de Rafael Moneo, en San Sebastián (España, 2007-11) (Fig. 05) y la catedral de Cristo de la Luz, de Craig W. Hartman, en Oakland (EEUU, 2005-08). Con lenguajes distintos, la luz que inunda el espacio conduce la mirada y el corazón de los visitadores hacia la gracia del alto, manifestando la vocación trascendente del edificio y conmoviendo el corazón.

\section{Orientación}

El libro que Joseph Ratzinger publicó en 1999 -Der Geist der Liturgie: eine Einführung (El espíritu de la Liturgia. Una introducción) - (Ratzinger 2001), inició un encendido debate en ámbito litúrgico sobre la cuestión de la orientación simbólica de la celebración. Aunque pudiera parecer un tema secundario del libro, constituía la auténtica clave de lectura de la concepción del culto cristiano del entonces prefecto de la Doctrina de la Fe. La orientación común de celebrante y pueblo durante la oración litúrgica determinaba no solo la posición del sacerdote - que Ratzinger parecía preferir vuelto hacia el ábside durante la plegaria eucarística一, sino también la misma forma y estructura de la nave, así como la situación del altar en el iglesia (Ratzinger 2001, 84-106) (Fig. 06). En el contexto de esta polémica es necesario enmarcar el significativo pronunciamiento de la Congregación para el Culto Divino del año 2000, en el que relativizaba la norma de la colocación coram populo de los nuevos altares. ${ }^{15}$

Sin entrar en el detalle de este amplio y complejo debate (Gerhards 2007, 167-187),16 consideramos que la principal consecuencia de esta discusión no ha sido tanto la construcción de nuevos altares vueltos 


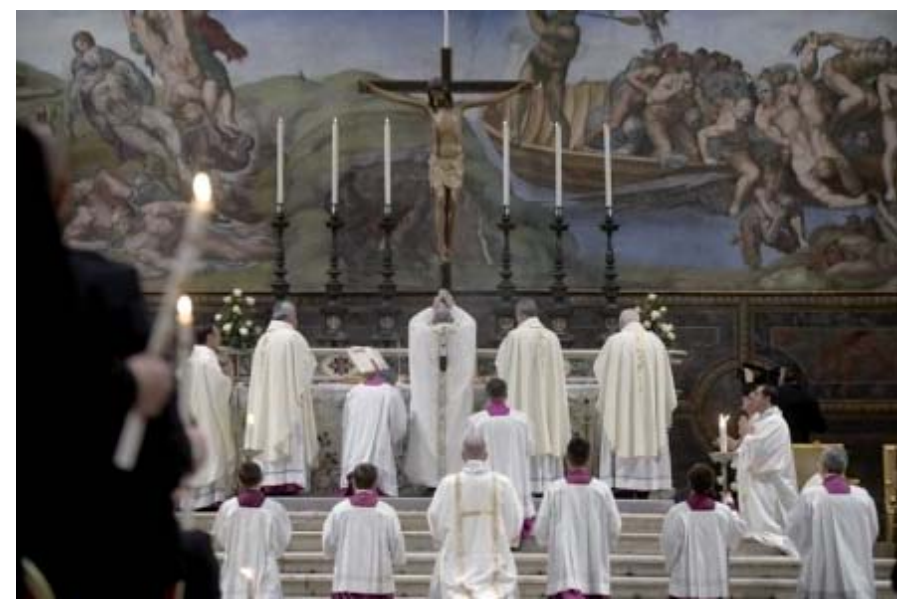

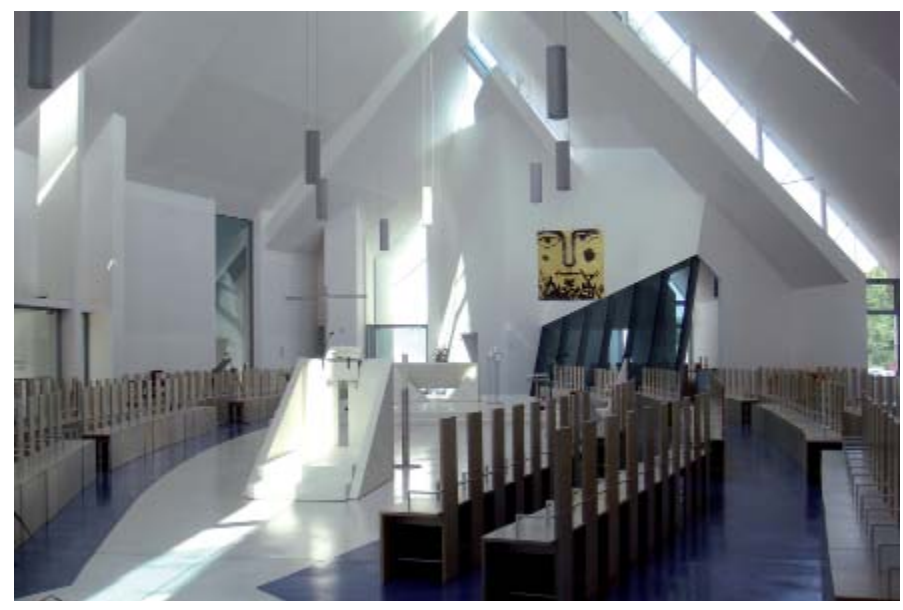

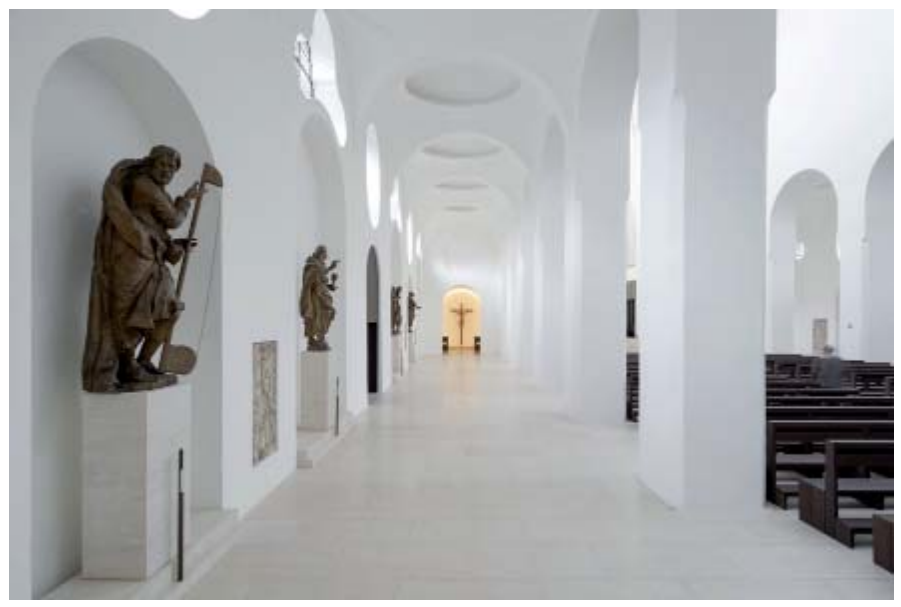

Fig. 06. El papa Francisco celebra la Santa Misa en la Capilla Sixtina durante de la fiesta del Bautismo del Señor (08/01/2017).

Fig. 07. Estudio Archicura, La Transfiguración, Mussotto d'Alba, Cuneo (Italia, 2008-10); en primer plano se distingue el ambón. Fig. 08. John Pawson, St. Moritz, Augsburg (Alemania, 2008-13). 
hacia el ábside, sino más bien que la planta central pierde su carácter absoluto como único modo de interpretar el espacio litúrgico según el Concilio. ${ }^{17}$ De este modo, en los últimos años se han favorecido organizaciones del espacio celebrativo donde la longitudinalidad del espacio se interpreta como apertura cósmica, cristológica y escatológica.

Algunas realizaciones recientes donde se valora positivamente esta orientación y apertura simbólica del espacio de la nave, en modos diversos, son la iglesia de Saint-François de Molitor, de Corinne Callies y Jean-Marie Duthilleul, en París (2000-05) o la iglesia de San Giovanni XXIII en el hospital de Bérgamo (Italia, 2012-14), del estudio Traversi+Traversi.

\section{Protagonismo del ambón}

Benedicto XVI dedica un punto de la exhortación apostólica Verbum Domini -que recoge las conclusiones del Sínodo de Obispos de 2008 sobre la Palabra de Dios en la vida y la misión de la Iglesiaa tratar sobre el ambón. Tras repetir los criterios tradicionales de la Reforma litúrgica sobre su colocación y diseño, añade que ha de ser un «elemento escultórico en armonía estética con el altar, de manera que represente visualmente el sentido teológico de la doble mesa de la Palabra y de la Eucaristía» (n. 68). Esta formulación del Magisterio es el resultado del desarrollo de la teología católica sobre la Palabra de Dios en el siglo XX, favorecida en buena medida por el Movimiento ecuménico. Ésta ha tenido como consecuencia directa la progresiva relevancia simbólica que ha adquirido - de nuevo - el ambón dentro de la iglesia.

Desde los años noventa ha sido más frecuente la polarización del espacio celebrativo en torno a los lugares del altar (celebración de la Eucaristía) y el ambón (proclamación de la Palabra), interpretados en mutua relación. De este modo, se equilibraba el protagonismo exclusivo que había tenido el altar en la arquitectura contemporánea desde los años cincuenta. Los recientes ambones de Giuliano Vangi en el santuario de San Giovanni Rotondo (2004) y la catedral de Arezzo (2012) interpretan acertadamente este principio teológico y magisterial.
Una consecuencia directa a la valorización del ambón y —más en general- de la liturgia de la Palabra es la propuesta del Communio-Raume (a la que antes hemos aludido). Dicha disposición facilita también la apertura del espacio celebrativo, que permite la integración de una cierta orientación simbólica. La propuesta original, rígidamente elíptica, ha sido interpretado de diversos modos en los últimos años. Algunos ejemplos de iglesias inspiradas en esta disposición son las italianas Jesús Redentor, de Mauro Galantino, en Módena (2005-08) y la Transfiguración, de Estudio Archicura, en Mussotto d'Alba (2008-2010) (Fig. 07), y la adaptación litúrgica de la iglesia de San Antonio, de Günter Pfeifer, en Stuttgart-Kaltental (Alemania, 2006).

\section{Relevancia de la reserva eucarística}

La insistencia del Movimiento litúrgico en la centralidad de la celebración eucarística en la vida cristiana, junto con el deseo de fomentar la participación activa, favoreció la centralidad y significatividad del altar dentro del aula litúrgica. Como consecuencia, el sagrario fue separado de él y tendencialmente situado en un lugar que no le robara protagonismo, hasta - frecuentemente - perder cualquier tipo de visibilidad. Junto con este fenómeno, a partir de los años sesenta se asiste en la Iglesia a una progresiva pérdida de devoción a Cristo-eucaristía reservado en el sagrario, contra la que firmemente clamó Pablo VI en la encíclica Mysterium fidei (03/09/1965), publicada pocas semanas antes de la conclusión del Concilio.

Especialmente después de la celebración del Año de la Eucaristía (2005), hemos asistido a una cierta recuperación de la práctica del culto y la adoración eucarísticos fuera de la misa. ${ }^{18}$ Esta tendencia ha sido fomentada y encauzada a través de algunas intervenciones recientes del magisterio papal, como la encíclica de Juan Pablo II Ecclesia de Eucharistia (2003) o la exhortación apostólica Sacramentum caritatis (2007), publicada por Benedicto XVI tras Sínodo de Obispos de 2005. En esta última se formulan algunas propuestas para incrementar la visibilidad y protagonismo del sagrario en la iglesia. A partir del principio de que el tabernáculo es uno de los «elementos propios del presbiterio» (n. 41), el papa Ratzinger señala 


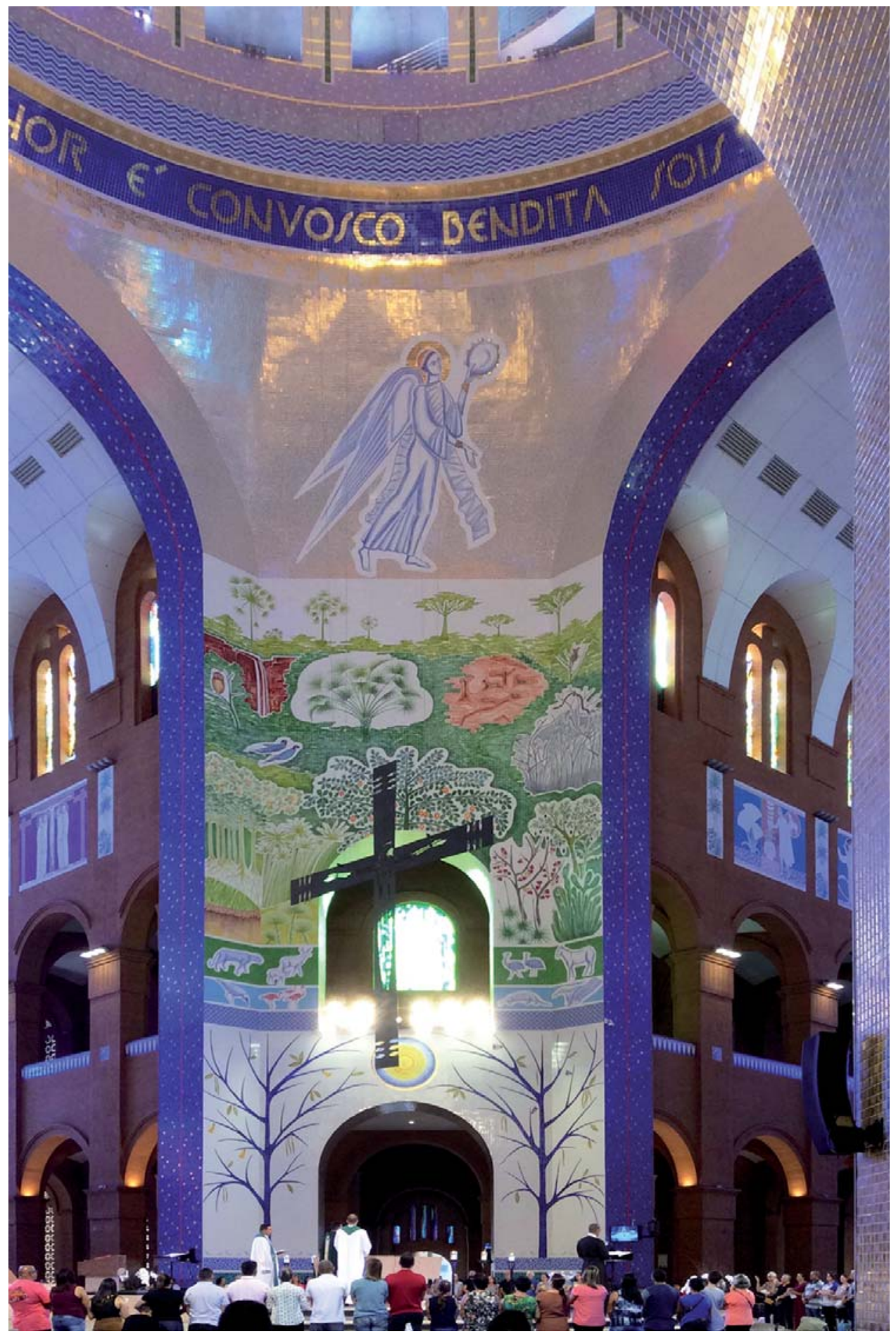

Fig. 09. Claudio Pastro, Santuario de Nuestra Señora Aparecida (Brasil, 2000ss); decoración del crucero y de la cúpula. 
la conveniencia de que éste se coloque en el mismo santuario: en el antiguo sagrario del altar mayor o en un lugar suficientemente alto y central. En las nuevas iglesias con capilla del Santísimo, ésta debe situarse igualmente en las proximidades del presbiterio (n. 69). Pocos años después, en la exhortación apostólica Verbum Domini (2010), añadirá que el «centro» (primarius locus) en el templo corresponde al sagrario (n. 68).

Algunas recientes construcciones que manifiestan esta nueva relevancia dada al sagrario son la iglesia del monasterio trapista de Santa María, de John Pawson, en Nový Dvùr (República Checa, 1999-2004); la parroquia del Buen Pastor, de VicénsRamos, en Ponferrada (España, 2008-10) o la iglesia de la comunidad monástica de Bose (Magnano, Italia), en la que desde hace unos años se ha situado un pequeño sagrario en el fondo del ábside.

\section{Uso extralitúrgico y devocional}

La focalización prioritaria en lo celebrativo para la definición del edificio de culto, a partir de los años cincuenta en Europa, no supo siempre integrar los fenómenos de la devoción individual y la piedad popular, manifestaciones privilegiadas de religiosidad que tradicionalmente han encontrado también su lugar en el edificio de culto cristiano. ${ }^{19}$ En este sentido, Benedicto XVI señalaba en Verbum Domini que «los espacios sagrados, también fuera de la acción litúrgica, sean elocuentes» (n. 68).

El rechazo por parte de amplios sectores el pueblo cristiano de la arquitectura moderna se debe, en buena medida, a su incapacidad para estar a la altura de estas expectativas religiosas (Mannion 1999, 4). Una consecuencia de la desafección de algunas comunidades hacia los lugares de culto construidos o remodelados entre los años sesenta y ochenta ha sido el difuso fenómeno de la espontánea transformación de estos espacios. Dichas intervenciones han adquirido frecuentemente la forma de resacralización y devocionalización del lugar de culto, pocas veces con acierto desde el punto de vista artístico. 20

Entre las obras que han sabido encauzar esta nueva sensibilidad podemos señalar —aunque se trate de obras muy distintas por su lenguaje y su contexto cultural - la reestructuración de la Moritzkirche, en Augsburgo (Alemania, 2008-13) de John Pawson (Fig. 08) y el nuevo santuario de San Josemaría Escrivá, en Gerona (Tarlac, Filipinas, 2010-14), de Alex Bautista.

\section{Iconografía y moderación de la abstracción}

La depuración iconográfica fue uno de los rasgos más característicos de la arquitectura católica desde los años que precedieron al Vaticano II en adelante, adquiriendo a veces extremos dramáticos. Esta tendencia se ha moderado a lo largo de los últimos años, dando lugar a un regreso a la figuración (Longhi 2017, 64). El aprecio hacia la imagen y, en general, hacia el papel de la sensibilidad y la sensualidad en la experiencia religiosa es algo característico de las primeras décadas del siglo XXI. Este aspecto ha sido seguramente fomentado por el desarrollo de la cultura popular y visual y, más específicamente, de las nuevas tecnologías de la información, la interconectividad y las redes sociales.

En el Directorio sobre la piedad popular y la liturgia (2002), la Congregación para el Culto Divino aboga por la estrecha vigilancia por la parte de la autoridad de la Iglesia hacia la dignidad, belleza y calidad del arte para la devoción (n. 18), señalando la importancia que para el edificio cristiano tienen prácticas como la veneración de las imágenes y la peregrinación (n. 19). ${ }^{21}$ A propósito del modo de integrar este tipo de iconografía en el proyecto de la iglesia, Benedicto XVI dirá en Sacramentum caritatis que «la iconografía religiosa se ha de orientar a la mistagogía sacramental» (n. 41).

No es infrecuente que, junto al proyecto arquitectónico y litúrgico, las nuevas construcciones cuenten desde el inicio con un proyecto iconográfico que prevé un programa de imágenes tanto litúrgicas como devocionales. Algunos ejemplos de esta tendencia son el proyecto decorativo de Claudio Pastro en el santuario de Nuestra Señora Aparecida, Brasil (iniciado en el 2000) (Fig. 09), o la basílica de la Santísima Trinidad, en Fátima (Portugal, 2004-07), de Alexandros Tombazis, y que cuenta entre los autores de su programa iconográfico al arquitecto Alvaro Siza. 


\section{BIBLIOGRAFÍA}

Baldovin, John Francis. 2010. «Idols and Icons. Reflections on the Current State of Liturgical Reform». Worship 84:386-402.

Barrie, Thomas, Phillip James Tabb, y Julio Bermudez, eds. 2015. Architecture, culture, and spirituality. Burlington: Ashgate.

Benedicto XVI. 2007. «Exhortación apostólica postsinodal Sacramentum caritatis». AAS 99:105180.

Benedicto XVI. 2010. «Exhortación apostólica postsinodal Verbum Domini». AAS 102:681-787.

Bermudez, Julio, ed. 2015. Transcending architecture. Contemporary views on sacred space. Washington DC: The Catholic University of America Press.

Bux, Nicola. 2008. La riforma di Benedetto XVI. Casale Monferrato: Piemme.

Cabié, Robert. 2000. «Les inconséquences des détracteurs de la réforme liturgique». Bulletin de Littérature Ecclésiastique 101:3-14.

Conferencia Canadiense de Obispos Católicos. 1999. Our Place of Worship. Ottawa: CCCB Publication Service.

Conferencia Episcopal Alemana. 1988. Leitlinien für den Bau und die Ausgestaltung von gottesdienstlichen Räumen. Bonn: Sekretariat der Deutschen Bischofskonferenz.

Conferencia Episcopal Alemana. 2003. Umnutzung von Kirchen. Beurteilungskriterien und Entscheidungshilfen. Bonn: Sekretariat der Deutschen Bischofskonferenz.

Conferencia Episcopal Española. 1987. Ambientación y arte en el lugar de la celebración. Directorio litúrgico-pastoral. Madrid: PPC.

Conferencia Episcopal Española. 2006. Ambientación y arte en el lugar de la celebración. Directorio litúrgico-pastoral $2^{\mathrm{a}}$ ed. Madrid: PPC.

Conferencia Episcopal Española, ed. 2014. Concilio ecuménico Vaticano II. Constituciones, decretos, declaraciones. $2^{\mathrm{a}}$ ed. Madrid: BAC.

Conferencia Episcopal Italiana. 1993. «La progettazione di nuove chiese. Nota pastorale». Notiziario CEI [3]:49-67.
Conferencia Episcopal Italiana. 1996. «L'adeguamento delle chiese secondo la riforma liturgica. Nota pastorale». Notiziario CEI [4]:105155.

Conferencia Episcopal Puertorriqueña. 2015 (1995). «Directorio litúrgico de la Eucaristía (cap. VI, Arte y ambiente litúrgico)». En Manual de Liturgia 5, editado por el Consejo Episcopal Latinoamericano, 410-432. Bogotá: CELAM.

Conferencia de los Obispos Católicos Irlandeses. 1972. The Place of Worship. Pastoral Directory on the Building and Reordering of Churches. $2^{\mathrm{a}}$ ed. Dublín: The Irish Institute of Pastoral Liturgy.

Conferencia de Obispos Católicos de Estados Unidos. 1978. Environment and Art in Catholic Worship. Washington DC: United States Catholic Conference.

Conferencia de Obispos Católicos de Estados Unidos. 2000. Built of Living Stones. Art, Architecture, and Worship. Washington DC: United States Catholic Conference. Traducido al español como Edificada con piedras vivas. Arte, Arquitectura y Culto. Normas y orientaciones sobre el arte litúrgico. México DF: Buena Prensa (2005).

Conferencia de los Obispos de Francia. 1971. L'église maison du peuple de Dieu. Liturgie et architecture. París: Cerf.

Conferencia de Obispos de Inglaterra y Gales. 1984. The Parish Church: Principles of Liturgical Design and Reordering. Londres: Catholic Truth Society.

Conferencia de Obispos de Inglaterra y Gales. 2006. Consecrated for Worship. A Directory on Church Building. Londres: Catholic Truth Society.

Conferencia de los Obispos Católicos Irlandeses. 1994. The Place of Worship. Pastoral Directory on the Building and Reordering of Churches. 3a ed. Dublín: Veritas.

Congregación para el Culto Divino y la Disciplina de los Sacramentos. 2000. «Responsum Congregationis». Communicationes 32:171-173.

Congregación para el Culto Divino y la Disciplina de los Sacramentos. 2001. «Instrucción Liturgiam authenticam». AAS 93:685-726. 
Congregación para el Culto Divino y la Disciplina de los Sacramentos. 2002. Directorio sobre la piedad popular y la liturgia. Madrid: BAC.

De Fusco, Renato. 1996. Storia dell'architettura contemporanea. $5^{\mathrm{a}}$ ed. Roma-Bari: Laterza.

Debuyst, Frédéric. 2003. Chiese. Arte, architettura, liturgia dal 1920 al 2000. Cinisello Balsamo: Silvana.

Faggioli, Massimo. 2010. «Quaestio disputata. Sacrosanctum Concilium and the Meaning of Vatican II». Theological Studies 71:437-452.

Faggioli, Massimo. 2016. «The Liturgical Reform from 1963 until Today... and Beyond». Toronto Journal of Theology 32:201-217.

Gamber, Klaus. 1989. Fragen in der Zeit. Kirche und Liturgie nach dem Vatikanum II. Ratisbona: Friedrich Pustet.

Gerhards, Albert. 2007. «Il dibattito sull'orientamento: riflessioni teologiche». En Spazio liturgico e orientamento. Atti del IV Convegno Liturgico Internazionale. Bose, 1-3 giugno 2006, editado por Goffredo Boselli, 169-182. Magnano: Qiqajon.

Gerhards, Albert, ed. 1999. In der Mitte der Versammlung. Liturgische Feirräume. Tréveris: Deutsches Liturgisches Institut.

Hoping, Helmut. 2011. Mein Leib für euch gegeben. Geschichte und Theologie der Eucharistie. Freiburg im Breisgau: Herder.

Introvigne, Massimo. 1996. Il sacro postmoderno. Chiesa, relativismo e nuovi movimenti religiosi. Milán: Gribaudi.

Juan Pablo II. 1989. «Carta apostólica Vicesimus quintus annus». AAS 81:897-918.

Juan Pablo II. 1999. «Carta a los artistas». AAS 91:1155-1172.

Juan Pablo II. 2003. «Encíclica Ecclesia de Eucharistia». AAS 95:433-475.

Kaczynski, Rainer, ed. 1976. Enchiridion documentorum instaurationes liturgicae, Vol. I (19631973). Casale Monferrato: Marietti.

Kieckhefer, Richard. 2004. Theology in Stone. Church Architecture from Byzantium to Berkeley. Oxford-Nueva York: Oxford University Press.
Klöckener, Martin. 2011. «La réception de la réforme liturgique du Concile Vatican 11. Une approche historique». La Maison Dieu 268 (4):41-62.

Kocik, Thomas, ed. 2003. The Reform of the Reform? A Liturgical Debate. Reform or Return? San Francisco: Ignatius Press.

Lang, Uwe Michael. 2007. Volverse hacia el Señor. Orientación en la plegaria litúrgica. Madrid: Cristiandad.

Longhi, Andrea. 2017. Storie di chiese, storie di comunità. Progetti, cantieri, architetture. Roma: Gangemi.

Mannion, M. Francis. 1998. «The Catholicity of the Liturgy: Shaping a New Agenda». En Beyond the Prosaic, editado por Stratford Caldecott, 11-48. Edimburgo: T\&T Clark.

Mannion, M. Francis. 1999. «Beyond Environment and Art in Catholic Worship». Antiphon 4:2-7.

Marques, João Luís. 2013. «Entre lo provisional y lo definitivo. Experiencias de las capillas-salón del Secretariado das Novas Igrejas do Patriarcado de Lisboa». Actas de Arquitectura Religiosa Cotemporánea 3:204-213. https://doi.org/10.17979/aarc.2013.3.0.5103.

Mosebach, Martin. 2007. Häresie der Formlosigkeit. Die römische Liturgie und ihr Feind. Múnich: Hanser.

Nichols, Aidan. 1996. Looking at the Liturgy. A Critical View of its Contemporary Form. San Francisco: Ignatius Press.

Nichols, Aidan. 2008. «Archi-Liturgical Culture Wars». New Blackfriars 89:522-542.

Post, Paul. 2006. «Dealing with the Past in the Roman Catholic Liturgial 'Reform of the Reform Movement'». Questions liturgiques 87:264-279.

Ratzinger, Joseph. 2001. El espíritu de la liturgia. Una introducción. Madrid: Cristiandad.

Richter, Klemens. 1998a. «Kirchenbau und Liturgie. Zur Wiedergewinnung und Weiterführung der liturgischen Bewegung in heutiger Raumgestalt». Kunst und Kirche 61:4-8.

Richter, Klemens. 1998b. Kirchenräume und Kirchenträume. Die Bedeutung des Kirchenraums 
für eine lebendige Gemeinde. Friburgo, Basilea, Viena: Herder.

Schloeder, Steven J. 1998. Architecture in Communion. Implementing the Second Vatican Council through liturgy and architecture. San Francisco: Ignatius Press.

Sternberg, Thomas, Walter Zahner y Albert Gerhards, eds. 2003. Communio-Räume. Auf der Suche nach der Angemessenen Raumgestalt Katholischer Liturgie. Ratisbona: Schnell \& Steiner.

Van Bühren, Ralf. 2008. Kunst und Kirche im 20. Jahrhundert. Die Rezeption des Zweiten Vatikanischen Konzils. Paderborn/Múnich/Viena/ Zúrich: F. Schöningh.

\section{NOTAS}

1. En realidad, dicho texto no hacía más que recoger el contenido normativo fundamental en este campo de algunas de las instrucciones (1964-67) con las que la Congregación de Ritos y el Consilium - el organismo especialmente instituido en Roma apenas unas semanas después de la promulgación de SC - deseaban aplicar la Reforma litúrgica conciliar. Dichas instrucciones fueron Inter Oecumenici (26/09/1964); Musicam sacram (05/03/1967) y Eucharisticum mysterium (25/05/1967) (Kaczynski 1976).

2. Baste pensar en el santuario de Santa María Reina de la Paz, de Gottfried Böhm, en Neviges (Alemania, 1964-68) o en la catedral de Santa María, de Kenzo Tange, en Tokyo (1962-65).

3. Dada la amplitud de nuestro estudio, tanto por el período tratado como por la abundancia de fuentes (documentos magisteriales y edificios construidos), nos limitaremos a señalar los textos, eventos u obras de arquitectura que consideramos más significativos o paradigmáticos para reconstruir esta historia.

4. Numerosas conferencias episcopales se han pronunciado oficialmente sobre la cuestión de la renovación litúrgica (sobre todo desde la perspectiva pastoral), también en lo relativo a los lugares celebrativos. No han sido tantas, sin embargo, las que han dedicado un documento específico, de suficiente extensión, a la construcción o adecuación de los espacios celebrativos, que ofrezca una imagen completa y orgánica del lugar de culto. En el presente trabajo citaremos únicamente este último tipo de documentos.

5. Entre ellas encontramos la forma y posición del altar, entendido como elemento exento situado en un lugar más próximo y bien visible fácilmente a los fieles; del tabernáculo, separado físicamente del altar; del ambón, como pieza significativa por su posición y tamaño; y de la sede del sacerdote, un asiento noble y de suficiente presencia, junto al que se colocan otras sedes menores (van Bühren 2008, 373). A estas experiencias se puede añadir la mayor relevancia simbólica del espacio para el bautismo dentro de la iglesia.

6. En este período, la organización del espacio se planificaba en buena medida a partir de la disposición del mobiliario litúrgico y a la relación de los lugares celebrativos entre sí (van Bühren 2008, 375).

7. En este documento, Juan Pablo II subraya la centralidad el Misterio Pascual como corazón teológico de la Constitución litúrgica, que lleva a reconocer la presencia viva de Cristo en la celebración, especialmente bajo las especies sacramentales (n. 7). La adoración y el silencio contemplativo constituyen, entre otros, algunos de los principales objetivos que alcanzar como metas de la renovación de la vida litúrgica (Carta apostólica Vicesimus quintus annus, especialmente los nn. 10, 14 y 23).

8. En Liturgiam authenticam (n. 7) se habla de una «nueva etapa de renovación [litúrgica]» («novam aetatem instaurationis [liturgicae]»). Dicho cambio de tendencia iniciaría con el la asamblea extraordinaria del Sínodo de los Obispos (1985), y el motu proprio Ecclesia Dei de 1988, por el que se concedía el permiso para la celebración de la liturgia preconciliar a determinados grupos de fieles de sensibilidad tradicional (Klöckener 2011, 41-62; Faggioli 2010, 44). Consideramos que en esta fase del magisterio litúrgico de la Santa Sede tuvieron un papel singular las personas que estuvieron al frente, durante algunos de estos años, de los dicasterios de la Curia implicados directamente en la interpretación de la Reforma. Se trata de Joseph Ratzinger, como prefecto de la Congregación para la Doctrina de la Fe (1981-2005) y de dos prefectos de la Congregación 
del Culto Divino y la Disciplina de los Sacramentos: el chileno Jorge Medina Estévez (1996-2002; 199698 como pro-prefecto) y el nigeriano Francis Arinze (2002-08).

9. En su exposición, el Catecismo se apoya fundamentalmente - desde el punto de vista magisterialen el Concilio y en la Institutio del Misal Romano.

10. La arquitectura para el culto de la última posguerra europea, según Juan Pablo II en la misma Carta, ha confirmado «la capacidad de inspiración que el tema religioso posee, incluso por lo que se refiere a los criterios arquitectónicos de nuestro tiempo» (n. 12).

11. Para Klemens Richter, esta disposición — que seguiría el auténtico espíritu de la Reforma conciliar- es el fruto de la profundización en los principios litúrgicos del Vaticano II (Richter 1998a, 4-8).

12. Este argumento apenas ha sido tratado en la bibliografía especializada (Nichols 2008, 522-542). Dado lo cercano de la época estudiada, este trabajo está necesariamente abierto a futuras investigaciones que lo completen, perfilen o corrijan.

13. La postmodernidad arquitectónica hunde sus raíces en el arte pop, y tiene como obra paradigmática el Learning from Las Vegas de Robert Venturi (1972). El arquitecto y teórico italiano Aldo Rossi (1931-97) se encuentra entre sus figuras más destacadas.

14. Las aportaciones de Julio Bermudez, Thomas Barrie y el ACS Forum son características de este nuevo interés hacia la trascendencia y sacralidad del espacio religioso (Bermudez 2015; Barrie, Tabb y Bermudez 2015).

15. Se había dirigido a la Congregación para el Culto Divino y la Disciplina de los Sacramentos una pregunta sobre la interpretación de un punto de la nueva Institutio del Misal Romano, publicada ese mismo año, donde se afirmaba que el modo de construir el altar versus populum «expedit ubicumque possibile sit» («conviene en todo lugar donde sea posible», n. 299). La respuesta oficial (Responsum Congregationis), del 25 de septiembre de 2000, indicó que el término expedit (conviene) indicaba solo una sugerencia. «Ubi possibile sit» (donde sea posible) hacía referencia a los lugares donde el espacio, la sensibilidad del pueblo o la presencia de un altar de valor artístico no indicasen lo contrario.

16. Nos limitamos a señalar la obra que, junto a la de Ratzinger, ha sido la más comentada. Se trata del libro de Uwe Michael Lang Conversi ad Dominum. Zu Geschichte und Theologie der christlichen Gebetsrichtung (Lang 2007 [2003]).

17. La principal crítica de Ratzinger a esta organización espacial provenía del riesgo de crear comunidades cerradas y autorreferenciales (Ratzinger 2001, 101-103).

18. El papa Francisco ha hablado en diversas ocasiones de la espiritualidad de la adoración. Por ejemplo, en la homilía en San Pablo Extramuros $(14 / 04 / 2013)$, en la rueda de prensa durante el vuelo de vuelta de la JMJ de Río de Janeiro (28/07/2013), y en una homilía en Santa Marta (22/11/2013).

19. Post ha señalado que estos aspectos más subjetivos de la experiencia religiosa son especialmente característicos de la espiritualidad de los últimos decenios (Post 2006, 270-273).

20. Dicho fenómeno ha sido poco estudiado en los estudios recientes. Señalamos dos importantes trabajos que han afrontado localmente este fenómeno: para el caso de Italia, puede verse Longhi 2017; y para las iglesias-salón del Patriarcado de Lisboa de los años 1960-80, Marques 2013.

21. El Directorio plantea el reto de acompañar, purificar e integrar las manifestaciones de la piedad popular y la liturgia, evitando cualquier tipo de contraposición (n. 23).

\section{PROCEDENCIA DE LAS IMÁGENES}

Fig. 01. http://fabiociardi.blogspot.com.

Fig. 02. jbdodane, https://commons.wikimedia.org.

Fig. 03. Wladyslaw, https://commons.wikimedia.org.

Fig. 04. Joe Mabel, https://commons.wikimedia.org.

Fig. 05, 09. Archivo del autor.

Fig. 06. http://www.photovat.com.

Fig. 07. https://www.jerusalem-lospazioltre.it.

Fig. 08. G. McCarragher, https://www.domusweb.it. 